\title{
9. Controlling influencer content through contracts: a qualitative empirical study on the Swiss influencer market
}

\author{
Catalina Goanta and Isabelle Wildhaber
}

\section{INTRODUCTION}

On 24 June 2019, the Swiss Foundation for Consumer Protection (Stiftung für Konsumentenschutz) filed a complaint with the Swiss Fairness Commission (Lauterkeitskommission) against Roger Federer and other celebrities, due to the lack of disclosure of advertisements in their social media posts. ${ }^{1}$ The Stiftung für Konsumentenschutz specified that all the social media personalities mentioned in their complaint promote products online (e.g. jewellery, sportswear, credit cards) without telling their followers that such posts are part of advertising deals made with various brands in exchange for financial gain.

Advertising on social media by celebrities and common folk alike is the new standard for digital marketing. This comes as no surprise, since social media audiences are on the rise, just like the number of content creators. ${ }^{2}$ While the Stiftung für Konsumentenschutz focuses on visible influencers, such as one of the most popular tennis players in the world, there are thousands (if not tens or hundreds of thousands) of smaller-scale content creators active on a plethora of platforms (e.g. YouTube, Instagram, TikTok, Snapchat). These creators engage with their audiences for the purpose of monetizing their content, and subsequently gain financial benefits in doing so.

As media focus shifted in the past decade from established broadcasters to any individual with a camera and Internet, this nurtured an emerging grey,

1 Stiftung für Konsumentenschutz, 'Beschwerden gegen Roger Federer, Michelle Hunziker und Co.' (Stiftung für Konsumentenschutz, 24 June 2019) https://www .konsumentenschutz.ch/medienmitteilungen/2019/06/beschwerden-gegen-roger -federer-michelle-hunziker-und-co/. All online sources accessed 26 August 2019.

2 Grace Duffy, 'YouTube Growth: Audience and Subscriber Numbers Are Rising' (Social Media Examiner, 9 February 2019) https:/www.socialmediaexaminer.com/ youtube-growth-audience-and-subscriber-numbers-rising/. 
non-regulated market: the monetization of influence on social media. ${ }^{3}$ The phenomenon of influencer marketing entails social media users with many followers endorsing goods and services for payments in money or kind, as they turn virtual popularity into real-world currency. It comes with promises like aspirational work, ${ }^{4}$ but also with challenges, such as the exploitation of vulnerable audiences (e.g. minors), deceitful behaviour (e.g. hiding paid endorsements) or misleading expertise (e.g. promoting harmful products). The status of influencers is legally uncertain (peers/professionals), and so is the division of rights and responsibilities within the service supply chain (agencies/ influencers/platforms). People seem to respond positively to reviews by their favourite YouTubers, regardless of the safety, ${ }^{5}$ health risks (e.g. anti-nausea pregnancy pills, detox teas), ${ }^{6}$ or hidden costs (e.g. Dutch vlogger Snapking asking children to call an $0-900$-number). ${ }^{7}$ Since there are no market entry barriers, business, legal and technological literacy are developed on the job, leaving both influencers and consumers vulnerable to exploitation. The UK Competition and Markets Authority, the Italian Competition Authority and the US Federal Trade Commission are consumer authorities that have already launched investigations into labelling online endorsements, and the Dutch Advertising Standards Committee has reprimanded companies and celebrities for non-disclosure. ${ }^{8}$ In addition, advertising disclosures and contract practices

\footnotetext{
3 See also Catalina Goanta and Isabelle Wildhaber, 'In the Business of Influence: Contractual Practices and Social Media Content Monetisation' (2019) 4 Schweizerische Zeitschrift für Wirtschafts- und Finanzmarktrecht 346.

4 See Chapter 6.

5 Jeena Sharma, 'Jojo Siwa's Claire's Makeup Recalled over Asbestos' (Paper Magazine, 10 June 2019) https://www.papermag.com/jojo-siwa-claires-asbestos -2638763293.html.

6 See for instance Makena Kelly, 'Senator Calls for FTC Investigation into "Dangerous Detox Teas" on Social Media' (The Verge, 4 June 2019) https://www .theverge.com/2019/6/4/18652918/ftc-blumenthal-influencer-marketing-instagram -youtube-kardashians-detox-tea.

7 Autoriteit Consument Markt (ACM), 'Consumers who Called YouTube Vlogger Snapking to Be Reimbursed' (ACM, 25 September 2017) https://www.acm.nl/en/ publications/consumers-who-called-youtube-vlogger-snapking-be-reimbursed.

8 See for instance Consumer and Markets Authority (CMA), 'Celebrities Pledge to Clean Up their Act on Social Media' (CMA, 23 January 2019) https://www.gov .uk/government/news/celebrities-pledge-to-clean-up-their-act-on-social-media; Italian Competition Authority (ICA), 'ICA Closes Second Moral Suasion on Influencers and Brands, Yet Opens Investigation into Possible Hidden Advertising' (ICA, 11 December 2018) https://en.agcm.it/en/media/press-releases/2018/12/ICA-closes-second-moral -suasion-on-influencers-and-brands-yet-opens-investigation-into-possible-hidden -advertising; Stichting Reclame Code, '\#Ad: Herken de reclame op internet' (Stichting Reclame Code, 27 August 2019) https://www.reclamecode.nl/news/campagne-ad-roept -influencers-op-open-te-zijn-over-reclame/.
} 
have already made it before courts around the world, including in the US and Germany. ${ }^{9}$

This chapter aims to unveil a side of influencer marketing that remains underexplored: the control of content through private law mechanisms. As the influencer market is inherently transactional, it is important to understand what business practices define this industry from the perspective of how legal risks are divided among contracting parties. In section 2, we give readers more insight into the business models shaping monetization practices used in influencer marketing, to identify the commercial interests embedded therein. Section 3 outlines a qualitative empirical exercise involving Swiss social media agencies, and discusses subsequent findings. Section 4 puts these factual observations in a legal context, by raising concerns regarding the distribution of liability in the influencer marketing supply chain. Section 5 concludes.

9 See Chapter 12. See also Celle Higher Regional Court (June 08, 2017 - Case 13 U 53/17), Germany; Chelsea Chinery, Shannon McAuliffe and Desiree Flores $v$ McFarland et al. [2017], Los Angeles County Superior Court, US; EHL Funding LLC $v$ McFarlane, et al. [2017], Supreme Court of the State of New York, US; Herlihy et al. v Fyre Media, Inc et al. [2017], New York Southern Court, US; Petrozziello v Fyre Media, Inc. et al. [2017], New York Southern Court, US; National Event Services, Inc. v Fyre Festival, LLC et al. [2017], Pennsylvania Eastern District Court, US; Oleg Itkin v McFarlane, et al. [2017], Supreme Court of the State of New York, US; PR Consulting v Luka Sabbat [2018], Supreme Court of the State of New York, US; Reel et al. v McFarland et al. [2017], Florida Southern District Court, US; Seth Crossno, et al. v Fyre Festival, et al. [2017], North Carolina State Court. In addition, there are several settlements between various influencers and the United States Federal Trade Commission (FTC), see for instance FTC, 'Lord \& Taylor Settles FTC Charges It Deceived Consumers through Paid Article in an Online Fashion Magazine and Paid Instagram Posts by 50 "Fashion Influencers" (FTC, 15 March 2016) https://www.ftc.gov/news-events/press-releases/2016/03/lord-taylor-settles-ftc -charges-it-deceived-consumers-through; FTC, 'Warner Bros. Settles FTC Charges It Failed to Adequately Disclose It Paid Online Influencers to Post Gameplay Videos' (FTC, 11 July 2016) https://www.ftc.gov/news-events/press-releases/2016/07/warner -bros-settles-ftc-charges-it-failed-adequately-disclose-it; FTC, 'CSGO Lotto Owners Settle FTC's First-Ever Complaint against Individual Social Media Influencers' (FTC, 7 September 2017) https://www.ftc.gov/news-events/press-releases/2017/09/ csgo-lotto-owners-settle-ftcs-first-ever-complaint-against. See also US Securities and Exchange Commission (SEC), 'Two Celebrities Charged with Unlawfully Touting Coin Offerings' (SEC, 29 November 2018) https://www.sec.gov/news/press-release/ 2018-268. 


\section{THE MONETIZATION SUPPLY CHAIN ${ }^{10}$}

Influencers can monetize content in at least two ways. First, they can earn money from different brands by promoting them through various advertising models on the influencer's social media channels, which is the phenomenon this edited volume focuses on, namely influencer marketing. Second, influencers can make money by using monetization services that are platform-specific, such as Google's AdSense program, available on YouTube, or the Live.ly model of making in-stream purchases (e.g. purchasing 'emojis', or tokens, with real-life money) for a favourite streamer. ${ }^{11}$ This chapter focuses on the first model.

With statistics showing that content created on social media is rapidly growing in popularity, ${ }^{12}$ it is understandable that advertising on social media channels has been following suit. Since ads are easy to skip, influencer marketing has become the main vehicle for brands to advertise their goods or services. Depending on their size, influencers may be:

- mega-influencers (millions of followers);

- micro-influencers (hundreds of thousands of followers); and

- nano-influencers (thousands/tens of thousands of followers).

As already pointed out in the Introduction of this book, the rise of content creators and the monetization which unfolded with the growth of their popularity have led to different paths towards becoming an influencer. More than a decade ago, when broadcasting services were not as used as they are today, common individuals would make videos for leisure purposes. These videos would become a record of improving various skills (e.g. make-up, video editing, singing), or even be used to address mental health issues as

10 This part is based on Goanta and Wildhaber (supra n 3).

11 Todd Spangler, 'Musical.ly Live-Streaming Stars Are Earning Thousands of Dollars from Adoring Fans' (Variety, 31 October 2016) https://variety.com/2016/ digital/news/musical-ly-live-ly-streaming-stars-earning-1201904864/. In addition, a rather different illustration that ought to fit the second model as well is the straightforward crowdfunding of various activities, through platforms such as Patreon, where fans can support creators with money. See Chapter 1, p. 12.

12 Megan Farokhmanesh, 'YouTube Is the Preferred Platform of Today's Teens' (The Verge, 31 May 2018) https://www.theverge.com/2018/5/31/17382058/youtube -teens-preferred-platform; Nathan McAlone, 'Young People Spend about Twice as Much Time Watching Netflix as Live TV, and Even More Time on YouTube' (Business Insider, 1 May 2017) https://www.businessinsider.com/teens-watching-netflix-youtube -more-than-tv-2017-5. 
a form of therapy. ${ }^{13}$ Yet growing numbers of fans and views, and generally the increase in time spent on social media platforms by different audiences, made content creation a lucrative activity with attractive rewards. Regular viewers started coveting the status of influencer, and new recipes for success were created. The management of this process, which entails strategizing around posting habits, curating content, but also managing clients and transactions, gradually started to be performed by new actors, such as public relations (PR) and branding or marketing agencies as well as influencer agencies. Currently, these agencies intermediate contact between influencers and other agencies and/or brands, and provide counselling for contracts, while sometimes also taking a percentage of the commercial deals concluded by or on behalf of influencers. ${ }^{14}$ This makes the service supply chain around influencer marketing rather complicated, as it has implications for the distribution of liability within the supply chain. Depending on the actors involved therein, we have proposed three models of intermediation: ${ }^{15}$

(i) Bilateral use of intermediation: both influencers and brands are represented by agencies;

(ii) Unilateral use of intermediation: either the influencer or the brand is represented by agencies;

(iii) No intermediation: brands contact influencers directly.

In Chapter 1, four business models were highlighted to explain the way in which brands interact with influencers. ${ }^{16}$ Below, we further discuss these models from the perspective of recognizing the commercial interests they entail.

In the case of affiliate marketing, the influencer agrees with the brand to share a tracking link when reviewing or promoting a product. Upon clicking the link, the viewer is sent to the brand's website, and any purchase made there (e.g. using a code provided by the influencer) is considered a converted sale for that influencer. In return, the influencer receives a commission (e.g. 10\%) for the conversion. Affiliate marketing is thus an effective marketing strategy, as advertisers have the rare opportunity to track sales and understand their return

13 Carla Marshall, 'Throwback Thursday: The First Videos from YouTube's Top Stars' (Tubular Insights, 3 October 2013) https://tubularinsights.com/throwback -thursday-first-videos-from-youtubes-top-stars/.

14 See for instance Taylor Lorenz, 'A New Lawsuit Could Transform How the Influencer Industry Is Regulated' (The Atlantic, 21 May 2019) https:/www.theatlantic .com/technology/archive/2019/05/why-tfues-lawsuit-against-faze-clan-matters/ $589900 /$.

15 Goanta and Wildhaber (supra n 3), 349.

16 Goanta and Ranchordas, see Chapter 1: Introduction. 
on marketing investment (ROI). ${ }^{17}$ The transaction behind this business model reflects one party (the brand) paying a commission to the other party (the influencer), in exchange for the latter sharing the tracking link/code on their social media channels and subsequently bringing sales to the brand. Although parties have clear commercial intentions, influencers often exclude affiliate links from their disclosure obligations, as they may consider themselves to only have such obligations in the case of endorsement/sponsorship deals. What is especially relevant when discussing commercial intention is the fact that tracking links often (if not always) come with perks, as the code shared by the influencer with their follower base will most likely have the form of or include a discount code. This means influencers can promote the affiliate link as a benefit they manage to secure from the brand they collaborate with, to the gain of their followers. The perception that a code provides viewers with a discount may therefore diminish or even hide the influencer's commercial intention of financially benefitting from the referral commission for converting clicks into sales. So far, no specific hashtags disclosing affiliate marketing stand out on social media, although this may depend on the transparency of given influencers, as well as on their creativity. Affiliate marketing is typically used for any influencer collaboration, regardless of the size of the influencer's fan base.

When dealing with sponsorships or endorsements, these transactions normally entail the influencer being paid for delivering certain advertising content on their social media channels. The lifespan of endorsement deals may either be limited to a specific campaign, or be defined in terms of a longer time frame during which the influencer acts as a brand ambassador. Section 3 of this chapter offers in-depth insights into the first example. The commercial intention of the parties is straightforward, as it entails the influencer being paid money directly, and not in kind or via commissions. If influencers opt to fully disclose these brand deals, they will communicate this type of business model to their audience by using hashtags such as \#ad, \#adv, \#advertising (as well as equivalents in various languages), or by making use of designated platform interface options (e.g. Instagram's 'Paid Partnership with ...'). However, the commercial intention behind the business model can also be veiled if the influencer chooses to express the collaboration in other terms, such as \#[influencer] $x[$ brand], \#[brand]girls, \#collab \#[brand]ambassador, \#partner, as it is not immediately clear that the influencer receives a direct financial remuneration on the basis of such posts, and it is equally opaque in terms of what exactly the influencer is paid for (e.g. consultancy in the form of co-designing products,

17 See for instance Rainer Olbrich, Carsten D Schultz and Patrick M Bormann, 'The Effect of Social Media and Advertising Activities on Affiliate Marketing' (2019) 13(1) International Journal of Internet Marketing and Advertising 47. 
advertising by making posts and/or stories). Moreover, the bigger the brand, the more likely it is it will work with mega-influencers. Conversely, smaller brands may choose to pay micro- or nano-influencers for campaign posts.

Barter or exchange is the third business model, whereby influencers advertise goods or services they receive for free (e.g. clothes, make-up, games, travel packages, hotel accommodation, dinners, etc.). In the case that an influencer reaches out to a brand to promote a product or service in exchange for a contribution in kind, the commercial intention can be carved out easily. However, other situations are less clear. Companies often offer influencers so-called PR packages, which are nothing more than gifts. At first sight, brands undergo such expenses to befriend influencers and establish a good relationship with them. However, upon further consideration, it may be that brands have a clear expectation that when they send out free products, influencers should promote them on social media. Depending on factors such as how well-known influencers are, their past performance with a given brand, or their genuine appreciation of a product, influencers may or may not feel the pressure of promoting freebies. Where a brand expects a review, and the influencer renders the expected performance, it can be argued that an implicit agreement is concluded. By sending the products, the brand makes an offer, which the influencer accepts through performance. Whatever the legal classification of this transaction may be, influencers have undeniable material benefits, which they may choose to label on social media through hashtags such as \#gifted, or \#presstrip, or by making posts where they praise certain brands or express thanks. However, it is very difficult to gauge whether an influencer adds a brand name because of such an obligation, or whether the reference is genuine and devoid of commercial interest, which makes this type of influencer marketing very difficult to spot, similarly to endorsement deals, and unlike affiliate marketing. This issue is particularly relevant for further reflection, since exchange seems to be one of the most popular forms of influencer marketing. ${ }^{18}$

The last business model is direct selling. Influencers may choose to diversify their business activities by creating their own companies and selling merchandise directly to their audience. Just as with affiliate marketing, there is no denying that the influencer has the commercial interest of selling (mostly) goods to their followers. A lot of influencers will launch their own e-commerce business, while some may choose to make use of existing e-commerce frameworks. Given that influencers are, in this case, sellers of goods or providers of services, they will be part of an even greater supply chain, going beyond

18 See World Federation of Advertisers (WFA), 'Influencer Marketing Study' (WFA, June 2018) https://www.annons.se/system/files/wfa_influencermarketingsurvey 26.6.18.pdf. 
marketing, and into production, transport, etc. A lot of influencers manage to circumvent the supply chain, however, by engaging in commercial practices such as drop-shipping. ${ }^{19}$ Drop-shipping is a supply chain management practice where the retailer has no stock of goods, but instead forwards customer orders and subsequent shipping requests to the manufacturer or another seller. Depending on the structure of the supply chain, various issues may arise with direct selling. These include the lack of professional expertise or diligence of influencers in running a business, leading to potential consumer damage or harm, as well as oversight for business and human rights, or unfair practices relating to hiding the provenance of the goods.

To work with influencers, brands (or the agencies representing them) may conclude agreements either in formal or informal ways. For the first, they employ so-called 'influencer agreements', which are framework contracts that will govern their collaboration, be it based on affiliate marketing, endorsement or exchange. With respect to the second, parties may conclude contracts via exchanges of messages on the social media platforms themselves, or via an exchange of e-mails. We can assume that the more established the influencer is, the more likely it is they take up some form of counselling. The same goes for the other party to the contract - the more established a brand or its representing agency is, or the more professional their business practices are, the more likely it is that some legal counselling will be involved in their contracting practices. ${ }^{20}$ While it can be argued that legal knowledge may be correlated with bargaining power, influencer marketing practice does not seem to be generally defined by a high level of legal literacy. One explanation for this industry feature is the legal uncertainty it entails: what is the legal status of influencers? What are their responsibilities? Who should be liable for non-disclosures, etc. ${ }^{21}$ With the industry being constantly reinvented, new models of advertising challenge whatever little certainty may be gathered through practice. Another explanation is that influencer marketing is open to anyone who is able to grow a social media account to the extent that it becomes interesting for brands. A nano-influencer with less than 10,000 followers will almost never be a professional advertiser who understands how to comply with legal standards. Asking the average small-scale influencer to be savvy in consumer law, business law, tax law and media law, to give a few examples, is unfeasible. Yet the influencer industry increasingly looks toward

19 See for instance https://www.oberlo.com.

20 Advocatie, 'MediaMonks lijft influencers van IMA in: Osborne Clarke en Van Doorne adviseren' (Advocatie, 21 August 2019) http://www.advocatie.nl/mediamonks -lijft-influencers-van-ima-osborne-clarke-en-van-doorne-adviseren.

21 See Chapter 10. 
nano-influencers, ${ }^{22}$ and we can assume that the knowledge gap between large brands and nano-influencers will only grow in the future. This has led to the proliferation of intermediaries managing influencers and sometimes negotiating the conditions of influencer agreements.

Revealing all the actors in the influencer marketing supply chain raises questions about the actual output influencers create. Especially at a time when content moderation becomes increasingly relevant, and influencers are both the benefactors as well as the victims of controversy or shock value because of its potential to generate revenue, it is important to reflect upon the role of all these actors. If influencers make a controversial post, are they to be held exclusively liable if there is any damage arising out of this post? What if the contract they have with a brand explains that the brand may veto content that goes against company policy?

While the categorization made in this section is based on anecdotal observations in the course of using social media, as well as on market research concerning commercial practices, little is known about the role intermediaries (e.g. agencies) have in controlling social media content that gets to be posted by influencers themselves. What is the awareness of intermediaries when concluding contracts on influencer marketing? How are legal risks divided? These are a few of the questions that arise when exploring the realm of contract law with respect to the activity of influencers. The next section looks into existing non-academic qualitative empirical studies of influencer marketing practices, and discusses the findings of our own qualitative research on the legal considerations agencies take into account when concluding influencer agreements.

\section{REACHING OUT TO SOCIAL MEDIA AGENCIES IN SWITZERLAND: A QUALITATIVE EMPIRICAL EXERCISE}

\subsection{Methodology}

Academic empirical research on the topic of influencer marketing has so far (including in this volume) focused on influencers or platforms. Yet influencer marketing has given rise to a considerable amount of intermediaries, in the form of agencies that work with influencers on behalf of brands, or represent influencers, as we have identified above. For this chapter, we wanted to highlight the involvement of intermediaries in the contractual relationships between the influencer and the brand providing the influencer with the

22 See section 3.1. 
opportunity for monetization, to better understand how monetized content is controlled contractually by the parties to these agreements.

We first looked into existing empirical research in this field. As legal literature has not yet covered this topic from an empirical perspective (especially not when dealing with the role of intermediaries), we turned to market research. Before presenting a few of the studies conducted by PR or influencer agencies, it must be specified that although they may be insightful in terms of market practices, the methodology relating to data collection or analysis is never defined, which raises concerns regarding the reliability of the results.

One of the largest studies recently conducted on intermediaries is a study by the Influencer Marketing Hub, that 'surveyed 830 marketing agencies, brands and other relevant professionals to determine their views and build insight into their thoughts on the industry in $2019^{\prime} .{ }^{23}$ This report places the influencer industry at a whopping size of $\$ 6.5$ billion in 2019 , compared to $\$ 1.7$ billion in 2016. Moreover, according to the survey deployed by the company, brands and agencies intend to increase their spending on influencer marketing in the coming year. A good part of the survey focused on how companies measure return on investment (ROI), and the main finding was that companies use metrics that reflect the goals of their campaign. Subsequently, 34 per cent of the 830 participants focused on awareness, measuring influencer marketing through view, reach and impression, whereas 35 per cent wanted the followers of influencers to perform a specific action (e.g. clicking a link), and would therefore use engagement as a measurement of the effectiveness of the campaign. The remaining 31 per cent focused on click-to-sale conversions. An interesting additional finding is that out of all participants, 63 per cent had experiences with fraudulent (or fake) influencers. ${ }^{24}$ This study did not include any legal considerations, but shows a clear interest in measuring the benefits of influencer marketing, which can be valuable when interpreting what is considered to be a suitable performance of an influencer agreement.

Another study worth mentioning was conducted by the World Federation of Advertisers. The study accounts for 38 respondents from 34 companies that are members of the Federation. ${ }^{25}$ Surprisingly, this survey tackles quite a few legal questions. For instance, one of the questions deals with whether the brand and influencer sign formal contracts. Seventy per cent of the 38 respondents answered this question in the affirmative, claiming they always conclude formal contracts. However, one brand acknowledges: '[We] very rarely [sign

23 Influencer Marketing Hub, 'Influencer Marketing Benchmark Report' (Influencer Marketing Hub, 2019), 2, https://influencermarketinghub.com/resources/influencer -marketing-benchmark-report-2019/.

24 Ibid, at 15

25 WFA (supra n 18). 
contracts] because we take an editorial rather than paid approach. There is a risk influencers do not deliver on expected ROI. But $90 \%$ of the time, we get what we want and more. ${ }^{26}$ The study further reveals the duplicity of influencer marketing, as 57 per cent of the advertisers who responded claimed to care about the reputation and credibility of an influencer, but at the same time 41 per cent of the respondents did not encourage transparency about the collaboration. Those brands who do want influencers to be transparent, make this part of the contractual obligations: 'We stipulate that when working with an influencer our teams must: Ensure that the exchange of goods, services and experiences is clearly disclosed in all relevant communication, by both the company and the influencers involved. We have a section in our dedicated policy which provides guidance and examples of how this can be done, both written and verbal.' In addition, the main three challenges experienced by brands in working with influencers are the lack of editorial control and subsequent reputation risk (42\%), non-compliance with regulations (38\%), and the lack of disclosure of the commercial relationship (33\%).

Apart from characterizing the industry by mostly focusing on details about how brands work with influencers and what budgets they allocate to their campaigns, a 2018 Linquia study of 181 US agencies also asked brands about FTC regulations. ${ }^{27}$ Eighty-seven per cent of respondents claimed they do request influencers to disclose their commercial interests in order to comply with FTC regulations, and 71 per cent stated they are familiar with the latest regulations.

Rakuten also generated an influencer marketing study, although most of it focuses on consumer perception, and the part of the survey dedicated to brands or agencies does not tackle any legally relevant aspects. ${ }^{28}$

To complement the existing non-academic landscape of empirical reports with a study that focuses on the contractual division of risk between a brand and an influencer, we conducted our own qualitative empirical research by reaching out to social media agencies in Switzerland. To better understand market practices, we launched an online questionnaire consisting of a total of 20 questions. On the basis of market research, we identified 81 agencies specialized in influencer marketing in Switzerland, and they were all contacted during May-June 2019. Out of the contacted agencies, seven filled in the

26 Ibid.

27 Linquia, 'The State of Influencer Marketing 2018' (Linquia, 2018) http://www .linqia.com/wp-content/uploads/2017/12/Linqia-The-State-of-Influencer-Marketing -2018.pdf.

28 Rakuten Marketing, 'Global Study by Rakuten Marketing Reveals the Growing Power of Influencers' (Rakuten Marketing, 14 March 2019) https://rakutenmarketing .com/media-and-press/global-study-by-rakuten-marketing-reveals-the-growing-power -of-influencers/. 
online questionnaire and one was available for a follow-up (semi-structured) interview. The latter also provided us with a standard contract.

As this empirical outreach exercise only resulted in an 8.6 per cent response rate, it surely cannot be used for further quantitative analyses, nor can it serve as a basis for drawing any descriptive statistics from its findings. However, the insights gathered through the use of open questions make a relevant contribution to a better understanding of how influencer marketing works in practice. We are not able to test any hypothesis using the results of this study, ${ }^{29}$ but they do give us some (albeit limited) insights into market practices which at least currently are mostly invisible to legal academia. The seven respondents, as well as the subsequent interview and standard terms obtained provide us with reasonably relevant insights into the market practices of social media agencies who collaborate with influencers. From this perspective, this study serves to raise awareness about the need to further explore the intersection of social media, advertising and law using empirical tools, to further reveal evidence regarding the functioning of this industry.

\subsection{Findings: Questionnaire}

The purpose of the questionnaire was to gain more insights into how agencies control content posted by influencers. The need to reveal this aspect arises out of the fact that while influencers are now at the centre of media attention when it comes to disclosing advertising, depending on how the advertising contract was set up, additional actors may be equally responsible for what content gets posted on social media on their behalf. The questionnaire includes marketing questions and legal questions. In what follows, we will illustrate a selection of answers.

When asked if they use influencers for marketing campaigns, the representatives of the social media agencies we contacted all agreed that influencer marketing is a very valuable contemporary tool in a wide spectrum of industries: 'We are an influencer marketing agency and rely on influencer marketing for companies in the gastronomy, tourism and food industries' (Respondent 2). The use of influencers in campaigns varied depending on the specificity of the agency's work: 'Yes, it does happen [that we use influencers for our marketing campaigns]. Not as standard and depending on [the] suitability [of] a valid solution/approach' (Respondent 5). In terms of how often campaigns make

29 See for instance John W Creswell, Research Design: Qualitative, Quantitative, and Mixed Methods Approaches (Sage 2014), 4. See also Lisa Webley, 'Qualitative Approaches to Empirical Legal Research' in Peter Cane and Herbert M Kritzer (eds), The Oxford Handbook of Empirical Legal Research (OUP 2010). 
use of influencers, some agencies replied that they use influencers in 10 per cent of their campaigns (Respondent 5). However, other agencies mentioned they employ influencers for every campaign (Respondent 1; Respondent 6). The number of influencers hired per campaign also varies according to our respondents: five agencies reported they work with 1-10 influencers at once, whereas two agencies reported that they hire between 10 and 25 influencers per campaign. Interestingly, none of the respondents seem to favour working with mega-influencers, and instead expressed a preference for working with micro- and nano- influencers.

The most popular platform with the Swiss agencies that responded to the questionnaire is Instagram, followed by YouTube and Facebook and generally by blogs. Some agencies reported also using TikTok, Snapchat, Vimeo, WeChat and LinkedIn, which shows the diversity of the audience agencies aim to engage with.

The measurement of success in these campaigns mostly consists of engagement and reach, which were the top two indicators used by the responding agencies. This can be explained by the goals all respondents agreed are the most important for their campaigns: reaching target audiences or new customers, and increasing brand awareness. Surprisingly, only two agencies reported that they had a vested interest in revenue conversion on the basis of marketing campaigns involving influencers.

Remuneration for influencer campaigns varies greatly in the responses. Respondent 1, for instance, emphasizes that their agency avoids paying per post, and would rather combine annual collaborations with individual campaigns. The prices per post mentioned by other respondents were included in price ranges such as: for Instagram posts, in the range of 100-450 Swiss francs and for blog posts 350-2,500 Swiss francs (Respondent 2), while testimonials commanded 0-5,000 Swiss francs (Respondent 4). Only two agencies reported having remunerated influencers with sums up to 10,000 Swiss francs (Respondent 3) or between 15,000 and 120,000 Swiss francs (Respondent 5). Moreover, five of the respondents indicated that their budgets for influencer marketing for 2019-2020 are on the rise. In addition, most of the respondents remunerate influencers according to a service fee, and none indicated paying influencers in kind (e.g. with products or services).

Five of the agencies that responded to our questionnaire described that they often conclude contracts with influencers themselves, whereas two indicated they conclude contracts with influencer agencies. It seems to be general knowledge that if a campaign is to include a mega-influencer, it is never the influencers themselves who the contract is signed with, but rather their management agency (Respondent 1). Six agencies further mentioned that these contracts are concluded in written form and signed by all parties included in the transaction, most often after negotiations via e-mail: "First clarify the 
conditions by e-mail, then always write contracts' (Respondent 6). One agency acknowledged the conclusion of contracts via direct messaging on the social media platforms themselves.

When it comes to the disclosure of advertising, agencies reported they prefer the use of hashtags by influencers (e.g. \#advertising), as well as disclosure through platform-specific interface features (e.g. Instagram's 'paid partnership with' indication). This is because agencies acknowledge the legal obligations imposed on them in terms of: 'Transparency about paid cooperation to the outside world, a work contract with the influencer with rights and obligations, partially labour law aspects, depending on whether influencers have single company or not, copyright and rights of use of content on own channels' (Respondent 1); 'Depending on the mandate and concept, certainly the usual in relation to competition law, intellectual property and federal law against unfair competition' (Respondent 5).

In turn, the legal obligations agencies believe it is important to impose on their contracting partners include: 'Transparency about paid cooperation externally, adherence to the agreed services according to the work contract, supply of reporting figures, exclusivity agreements' (Respondent 1); 'Transparency regarding payment, depending on the campaign also visual, content $\&$ time obligations. If these are not adhered to, there will be no payment' (Respondent 2). In addition, one agency indicated that one obligation they impose on the influencers they work with is to report on follower statistics (Respondent 7).

A very interesting finding relates to the way in which agencies manage the risks associated with influencer marketing (e.g. controversial behaviour, lack of control over contributions, premature deletion of advertising entries), which includes reliance on a lot of informal mechanisms in addition to contractual ones. For instance, agencies informally check the reputation of influencers before the conclusion of the contract, and engage in close relationship management during the collaboration by setting clear rules and expectations. A lot of the rules become formalized through contractual mechanisms dealing with payment (e.g. no pre-payment), or through blacklisting practices within the body of the contract.

\subsection{Findings: Interview and Contract Analysis}

One of the respondents to the survey agreed to be interviewed via phone. This section gives an overview of the main qualitative insights obtained during the interview, and further elaborates on the content of a set of standard terms usually sent by the agency to influencers they collaborate with. The interview took approximately 20 minutes. It must be noted that since this is only one interview, we cannot generalize it in any way. We therefore do not imply that the discussed practices are the same as those of every advertising agency in 
Switzerland that works with influencers. This being said, a lot of the practices reported therein can be triangulated with the market research discussed earlier in this section, leading to the possibility that, globally, the contractual issues agencies deal with when concluding contracts with influencers are very similar. This is in line with the cross-border nature of influencer marketing. While factors such as language may define a targeted audience, influencer marketing rarely has local focus, especially given that recommender systems may diffuse influencer content even beyond the desired targeted reach.

\subsubsection{The interview}

The agency representative mentioned that they regularly work with a large network of influencers, most of whom they know personally and therefore trust. The interviewee distinguished between influencers who are hired per campaign (e.g. to make a specific number of posts), and those who are hired through sponsorship contracts, referred to as influencers 'under contract', because they commit to becoming brand ambassadors. This particular agency mentioned that they negotiate the terms of the agreement, and subsequently conclude formal contracts via e-mail. They refer to contracts as 'briefings', and they are drafted by the agency, and not by a lawyer. Even though the agency does not work with a lawyer, the interviewee reported that they never make agreements via direct messaging on social media platforms.

When asked what the biggest legal issues faced by the agency were, the interviewee reported that non-performance happens quite often, and it may take various shapes, such as not respecting the number of posts, their order, or use of hashtags, @ tags as instructed by the agency. Sometimes, influencers fail to implement the indicated disclosure hashtags showcasing the commercial nature of a given collaboration. When faced with such situations, the agency representative indicated they simply withhold the fee from the influencer because the contract was not performed at all, or it was not performed properly. The interviewee added: 'Especially for larger contributions/blog posts, the influencer must first have the contribution approved by us/by the customer. This applies to both image and text ... Once, we pointed out to an influencer to delete a picture because (a) it was not accepted by us and (b) it did not comply with the customer's guidelines.' However, the agency has not encountered extremely controversial content posted by its influencers: 'Since we mostly deal with unproblematic topics, this has never been the case before. However, we check the influencers carefully beforehand and for more complex topics/ campaigns, we have the contributions accepted before they are posted.'

Another point made by the interviewee was that apart from withholding the performance of their own side of the bargain in the case of non-performance by the other party, the agency will most likely never book a problematic influencer again. This is another sign of using informal mechanisms for the 
application of legal norms, this time in the shape of informal accountability or sanction measures outside the contractual framework.

\subsubsection{The contract}

Apart from answering questions relating to influencer marketing practices in Switzerland, the interviewee also sent us a so-called 'Campaign Briefing', a three-page document seen as the contract between the agency and the influencer. This document is described and analysed below.

The briefing is an informally drafted document which seems to form the legal foundation of the campaign collaboration between the agency and the influencer. It describes a specific campaign, and asks the influencer for clearly defined deliverables, in this particular example relating to a shortened link (bit. ly), most likely used for affiliate marketing in a giveaway, which the agency asks the influencer to add:

- in the Instagram bio (optional);

- as text in the caption to a post (optional);

- as swipe-up in an Instagram story (mandatory);

- in a blogpost (mandatory).

A giveaway is a competition a brand may organize with an influencer. To enter a giveaway, users are regularly asked to either follow the page of the brand, make a comment and tag other users, or make posts and use the hashtags of a specific campaign. In exchange, the influencer promises their followers products or services. This activity increases the engagement of the influencer, because users see this as a gratuitous act that does not require them to purchase anything, but on the contrary, to make a gain.

In the briefing, the influencer is asked to make timely plans for the posts required from them, and a specific week is indicated as a posting timeline. Examples of posts in this particular briefing include a picture post and a two to four sequence story (on Instagram), as well as a separate blog post. The briefing also indicates that the influencer must post campaign-specific hashtags, and refers to campaign-specific instructions relating to some of the content (e.g. what the influencer should wear, how the photos should look, whether they should be indoors, outdoors). In addition, the document also refers to 'No Go's', namely actions or content prohibited under the campaign. This is very much dependent on the content of the campaign, but may vary from, for example, not showing alcohol in a photo to protect underage followers, to not posting photos in full sunlight to avoid skin redness.

The briefing may get technical in terms of which hashtag should be used in which post, as a condition of performance meant to lead to user engagement. For this reason, the agency prohibits the use of tags in comments, as 
it wants such brand tags to be featured in the description of an image post for more prominence. Sometimes, the agency even provides the influencer with a caption for the description, although it is preferred that influencers be genuine in their posts, and thus adapt the message to their own editorial voice.

The briefing does not specify for how long the posts (Instagram or blog) need to stay online. After the campaign, the briefing indicates that the agency expects the following analytics:

- the number of story views;

- the number of link clicks in the story; and

- the number of blog post views.

The final section of the briefing is dedicated to payment, which is done after the campaign finishes.

\section{INFLUENCER AGREEMENTS UNDER SWISS LAW}

The main goal of reaching out to agencies was to unveil the contractual practices involved in influencer marketing, and to better understand how parties shape the balance of rights and obligations. In what we have seen above in section 3 , the transactions between these parties often entail both formal (contractual) as well as informal (extra-contractual) accountability mechanisms, which we will elaborate on in what follows.

\subsection{Formal (Contractual) Accountability Mechanisms}

With respect to the first type of accountability mechanisms, in Switzerland, the unfair trading regulations (Act against Unfair Competition, UWG), ${ }^{30}$ aim to protect fair competition and balance market interests with individual consumer interests, ${ }^{31}$ and tackle unfair commercial practices that apply, inter alia, to the advertising industry. The market impact of such practices, as well as potential enforcement mechanisms protecting public interests, play a key role in the debate around the optimal regulation of the influencer marketing phenomenon.

30 Federal Law on Unfair Competition of 19 December 1986 (UWG).

31 See for instance the commentaries for Arts 1 and 2 UWG, Peter Jung and Philippe Spitz (eds), Bundesgesetz gegen den unlauteren Wettbewerb (UWG) - Kommentar (Stämpfli 2010). See also Jan Kabel and Frauke Henning Bodewig, 'Should the Objectives of the Rules on Unfair Competition Be the Protection of Competitors, or Consumers, or of Other Interests? How Should Any Conflict between these Objectives Be Resolved?' International Report for the LIDC Amsterdam Congress on Competition Law, 6. 
However, the very few cases that have attracted the attention of competition and/or consumer authorities around the world have not shed sufficient light on the contractual practices surrounding influencer marketing. Revealing these practices can help us answer the question of how liability is divided between the influencer and their contracting parties when harm arises out of the content posted by the influencer. Unfair commercial practices standards impose a general prohibition against practices that may impact the relationship between competitors, or between suppliers of goods/services and their contracting parties. According to the UWG, this prohibition has a wider scope of application, as it does not only envisage business-to-consumer (B2C) transactions, but may be imposed on any other stakeholders, such as the media, ${ }^{32}$ or even scientists. ${ }^{33}$ If case law develops to include a trend of interpreting hidden endorsements made by the influencer with respect to a specific brand as misleading statements, then contract clauses between influencers and brands (or their intermediaries) can be used to determine which party had knowledge of and control over the content posted by influencers.

To first categorize influencer agreements from the perspective of Swiss contract law, Article 19 of the Swiss Code of Obligations (CO) enshrines the principle of contractual freedom, as the parties are free to establish their obligations. When trying to assess the nature of agreements used in the monetization of content on social media, the qualification of the contract consists in linking it to a specific contract, provided for by the $\mathrm{CO}$, or to an innominate type of contract, not regulated by law. In order to make a qualification, we interpret the contract, seeking 'the real and common intention of the parties'.$^{34}$ If the real and common intention of the parties cannot be identified, the interpretation is made according to the principle of trust. Once the content of the contract has been established, the legal nature of the agreement is determined by reference to the legal constituent elements of the contracts that come into consideration and the criteria laid down by case law and doctrine. ${ }^{35}$

In qualifying influencer agreements, in prior scholarship we advanced three options: ${ }^{36}$ (i) contracts for work and services; ${ }^{37}$ (ii) agency contracts; ${ }^{38}$ or (iii)

Decision of the Federal Tribunal BGE 117 IV 193.

Peter Jung, 'UCP-Directive and Swiss Law against Unfair Competition' (2016)

2 Journal of European Consumer and Market Law 102, 103.

${ }_{34}$ Art 18(1) CO.

35 Ibid. See also Federal Supreme Court 4A.200/2015, 3.9.2015, consid. 4.

36 Goanta and Wildhaber (supra n 3), 352.

37 Art 363 et seq. $\mathrm{CO}$.

38 Art 394 et seq. CO. 
innominate contracts. ${ }^{39} \mathrm{We}$ will briefly discuss some of the implications of each of these options for the division of liability within the supply chain.

First, if we are to qualify influencer contracts as contracts for work and services, in the situation in which the influencer fails to deliver the promised performance, or does not deliver within the promised time frame, the brand/ agency is entitled to terminate the contract. ${ }^{40}$ Moreover, the $\mathrm{CO}$ imposes an obligation on the client (in this case the brand/PR agency) to inspect the work performed by the contractor (the influencer) ${ }^{41}$ These provisions seem to reflect a lot of the contractual clauses discussed in section 3. However, the $\mathrm{CO}$ also states that if the work delivered by the contractor is defective (e.g. influencer content is considered misleading), the contractor is not to be held liable if the customer is at fault for these defects. ${ }^{42}$ This Article may very well be interpreted to mean that if an influencer post is considered misleading because the brand/agency specifically asked the influencer to not disclose its nature, the influencer could go against the brand/agency for any loss suffered in the case of fines, etc. The influencer may still be held liable from a perspective of public law/mandatory rules (e.g. UWG) for misleading advertising, but the contractual basis that might have generated the unfair commercial practice could enable further liability in the supply chain.

In the case of agency contracts, the agent (the influencer) owes the principal (the brand/PR agency) the 'diligent and faithful performance of the [entrusted] business' ${ }^{43}$ Compliance with the instructions of the principal is a core obligation placed on the agent. To this extent, if the agent receives instructions, they may not deviate unless the agent is not able to obtain explicit permission for the deviation, and may safely assume that the principal would agree with such deviations. ${ }^{44}$ This can be illustrated with a situation where the influencer receives instructions on what to include in a social media post. If those instructions cannot be followed, an influencer may deviate without explicit permission only if they could consider that such permission would have been forthcoming if the brand/agency had been aware of this. If these conditions are not met, the influencer contract is considered to have been performed only if the brand/agency takes on any liability for damage resulting from not following the instructions. In the opposite situation (e.g. the influencer takes a photo of alcohol when the instructions specify to avoid alcohol in a picture), the brand/agency may hold the influencer liable for non-performance. In this case,

$39 \quad$ Art 394(2) CO.

40 Art 366(1) CO. See also Art 368 CO.

41 Art 367(1) CO.

42 Art 369 CO.

43 Art 398(1) CO.

44 Art 397 CO. 
if mandatory rules protecting, for example, minors against alcohol advertising are applied to sanction the influencer, not only will the latter not be able to go against the brand/agency for any resulting damage, but the brand/agency will also be liable in the contractual relationship with the brand/agency.

Lastly, innominate contracts are the most difficult to assess, as their shape depends on how the obligations undertaken by the parties are to be interpreted. In principle, if any of these obligations leads to a possibility of a contract being, for example, a sui generis contract for work and services, a judge ought to determine whether and to what extent the $\mathrm{CO}$ provisions for contracts for work and services apply.

This brief overview gives several illustrations of the provisions which may be applicable to the determination of further rights and obligations for influencers and their contracting parties. As we have discussed earlier in this chapter, it is reasonable to assume that influencer agreements are short documents which only account for a limited number of scenarios resulting from the contract. This raises two additional questions.

On the one hand, regardless of how the parties determine the content of a contract, mandatory norms will trump any clause drafted by the parties. ${ }^{45} \mathrm{In}$ particular, additional rules are designed to protect employees, tenants or consumers. In the case of contracts for work and services, agency or innominate contracts, mandatory limitations to the rules governing these special contracts are found in general contract law. For instance, a contract between a brand and an influencer, with terms that are impossible, unlawful or immoral, is deemed void, and clauses contravening mandatory rules protecting public policy, morality or rights of personal privacy are inadmissible. ${ }^{46}$ This may not only lead to additional sanctions from other sources of law (e.g. criminal law), but it may also entail that the contractual basis on which one party could turn against the other for incurring losses may be dissolved. As for the additional sources of law, public interests relevant for influencer marketing can also be found in, for example, limiting the advertising of certain products (e.g. the advertising of tobacco or alcohol) or protecting certain categories of legal subjects (e.g. minors), and in the UWG, which sanctions the use of deceptive advertising. ${ }^{47}$

On the other hand, from the perspective of contract law, perhaps more important in practice than what parties stipulate in their contracts and which may contravene to mandatory law, is what parties do not stipulate. Given the succinct nature of influencer agreements, it is likely that parties will not manage to successfully deviate from the default rules enshrined in the CO.

Goanta and Wildhaber (supra n 3), 353.

Arts 19 and 20 CO.

Jung and Spitz (supra n 31). 
As an illustration, in both contracts for work and services and agency contracts, 'the contractor generally has the same duty of care as the employee in an employment relationship'. ${ }^{48}$ This raises the question of how to interpret a duty of care in the context of an influencer agreement, whereby the latter is very likely only going to include an explicit reference to deliverables (e.g. the number of posts), but not the quality of work that is expected from the influencer. If parties fail to define a duty of care that reflects their expectations, a court interpretation may lead to a more stringent duty of care being imposed on the influencer in practice than envisaged by the influencer under the terms of the agreement.

\subsection{Informal (Extra-Contractual) Accountability Mechanisms}

In parallel with the legal remedies that both brands and influencer have available in the case that the agreement does not go according to initial expectations, the surveys referenced in section 3 also revealed that agencies employ other practices to single out influencers who break the terms of the agreement. Such mechanisms may include blacklisting, whereby a brand/agency makes sure an influencer who violated an influencer agreement is not employed again by labelling them as untrustworthy, or using reputation mechanisms (e.g. word of mouth, influencer analytics) to verify the untrustworthiness of a new influencer. This seems to be increasingly more important for brands/agencies, given the ease with which influencers may purchase fake followers, ${ }^{49}$ or more skilfully fake engagement and endorsements. ${ }^{50}$

While original experiences with influencers may be informative and reliable, the same can't be said for data-driven information which brands may retrieve on targeted influencers. The creation of tools aimed at measuring the performance of influencers that a brand/agency may not be familiar with at all - especially given the rise of nano-influencers - is understandable, if not necessary. Yet the number of available tools, combined with the lack of

48 Arts 364(1) and 398(1) CO.

49 Michael Aynsley, 'Want to Buy Instagram Followers? This Is What Happens When You Do’ (Hootsuite, 20 March 2017) https://blog.hootsuite.com/buy-instagram -followers-experiment/.

50 See for instance Mediakix, 'Are Fake Instagram Influencers Deceiving Brands?' (Mediakix, 4 August 2017) https://mediakix.com/blog/fake-instagram-influencers -followers-bots-study/; Julianna Vorhaus, 'Instagram Influencer Rates' (Influence. co, 19 February 2018) http://blog.influence.co/instagram-influencer-rates/; Alex Kantrowitz, 'Facebook Removes 10 Instagram Algorithm-Gaming Groups with Hundreds of Thousands of Members' (Buzzfeed News, 11 May 2018) https://www .buzzfeednews.com/article/alexkantrowitz/facebook-removes-ten-instagram-algorithm -gaming-groups-with\#.tu6765MwX. 
transparency on how they work, turn the profiling of influencers on the basis of analytics which can be explored via the Application Programming Interfaces (APIs) of social media companies, into a guessing game, even though data analyses are supposed to offer a higher degree of reliability than the subjective recommendations of industry participants. ${ }^{51}$ Tools such as IG Audit, that are supposed to check Instagram profiles for fake followers, have no information whatsoever regarding how the inherent calculations are made, or definitions relating to what a fake follower actually entails. Even though the need for such tools is clear, inaccurate predictions may harm the interests of influencers, who are already under intense pressure to cope with the unilaterally ever-changing algorithms behind the recommender systems of social media platforms.

\section{CONCLUSION}

This chapter focused on furthering the existing legal explorations of contractual practices employed in the context of influencer agreements. Influencers often come into the spotlight for failing to disclose advertising, yet they are part of a complex supply chain that may, depending on the situation, equally be held liable for the influencer's actions. This chapter aimed at further reducing the legal uncertainty surrounding influencer marketing by first clarifying business models from the perspective of the commercial intention, and subsequently by sharing the findings of a qualitative empirical exercise undertaken on several social media agencies in Switzerland.

Although not generalizable, the findings of the questionnaire used in this study match some of the information generated by non-academic market research. For this reason - among others - in spite of the low response rate, we included this outreach in our analysis, in an attempt to raise awareness of the need for further empirical research on this topic. Contracting practices between influencers and brands/agencies remain highly opaque for legal literature, which generally focuses on public law conditions that influencer content ought to abide by. As influencer marketing is an intensifying trend, it is all the more necessary to first understand how it works, who its stakeholders are, and what additional legal issues may arise out of the transactions it gives rise to.

51 For an overview of Facebook's Graph API see Catalina Goanta and Stephan Mulders, "Move Fast and Break Things": Unfair Commercial Practices and Consent on Social Media' (2019) 4 Journal of European Consumer and Market Law 136. 